\title{
A Vertebral Bite by an Aneurysm
}

FRANK VERHOEVEN, MD, Fellow, CHRU Besançon; DANIEL WENDLING, MD, PhD, Professor, Department of Rheumatology, CHU Jean Minjoz, 2 Boulevard Fleming, F-25030 Besançon, France. Address correspondence to Prof. D. Wendling. E-mail: dwendling@chu-besancon.fr. J Rheumatol 2015;42:347; doi:10.3899/jrheum.140319

The clinician must keep in mind that vertebral pain with osteolysis can be secondary to chronic rupture of an aorta aneurysm ${ }^{1,2,3}$.

A 73-year-old man with a history of an aortic prosthesis for an abdominal aorta aneurysm, a prostatic resection, and a cataract, presented in the emergency service for abdominal pain and high, right lumbar pain. There were no triggering factors and examination showed no spinal or neurological signs. Biological tests showed only elevated C-reactive protein $(4 \mathrm{mg} / \mathrm{dl})$ without hyperleukosis and normal procalcitonin. Blood cultures were all sterile. Computed tomography examination showed a voluminous abdominal aorta aneurysm with osteolysis of L1 (Figure 1). The anterior part of the L1 vertebral body was affected by the aneurysm and there was a mass in proximity with the posterior part of the aneurysm that infiltrated the vertebral body. This mass was the result of a chronic rupture of the aneurysm corresponding to a hematoma infiltrating the bone. Management was limited to symptomatic treatment because of excessive surgical risks. To date the patient remains well.

\section{REFERENCES}

1. Aydogan M, Karatoprak O, Mirzanli C, Ozturk C, Tezer M, Hamzaoglu A. Severe erosion of lumbar vertebral body because of a chronic ruptured abdominal aortic aneurysm. Spine J 2008;8:394-6.

2. Saiki M, Urata Y, Katoh I, Hamasaki T. Chronic contained rupture of an abdominal aortic aneurysm with vertebral erosion: report of a case. Thorac Cardiovasc Surg 2006;12:300-2.

3. Jacquot JM, Strubel D, Joyeux A, Di Castri A, Finiels H, Nachar H, et al. Sealed rupture of an abdominal aortic aneurysm with chronic vertebral destruction as the first manifestation. Contribution of computed tomography to the diagnosis. Rev Rhum Engl Ed 1996;63:377-9.

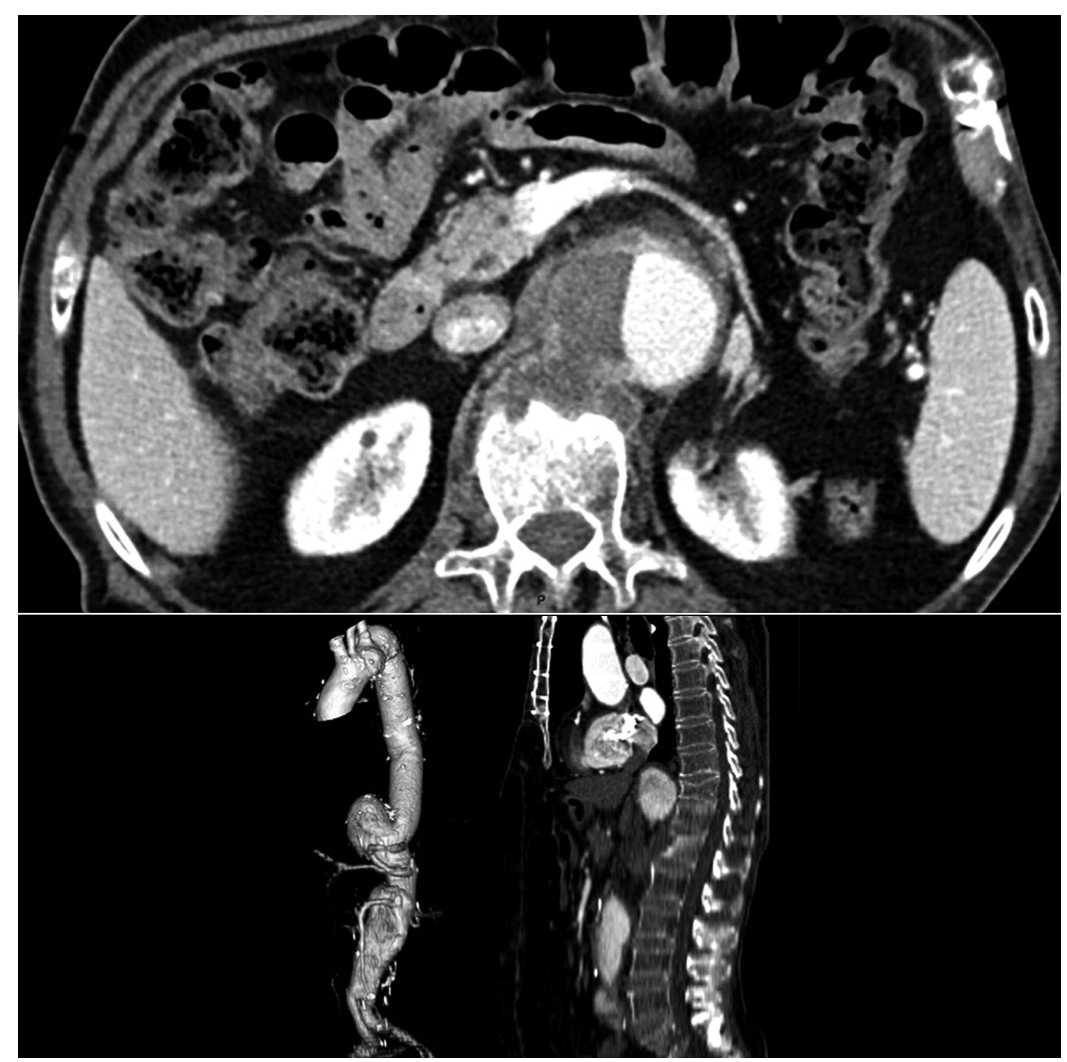

Figure 1. Computed tomographic scan showing a voluminous abdominal aorta aneurysm, with osteolysis of the anterior part of L1 secondary to a hematoma infiltrating the bone in a context of chronic rupture. 